\title{
The First Population Simulation for the Zalophus japonicus (Otariidae: Sea Lions) on Dokdo, Korea
}

\author{
Yoon-Ji Lee ${ }^{1} \mathbb{D}$, Giphil Cho ${ }^{2} \mathbb{D}$, Sangil Kim ${ }^{3} \mathbb{D}$, Inseo Hwang ${ }^{4}$, Seong-Oh Im ${ }^{4}$, Hye-Min Park ${ }^{4}$, Na-Yeong Kim ${ }^{1}$, \\ Myung-Joon Kim ${ }^{1}$, Dasom Lee ${ }^{1}$, Seok-Nam Kwak ${ }^{5}$ and Sang-Heon Lee ${ }^{1, * \mathbb{D}}$
}

check for updates

Citation: Lee, Y.-J.; Cho, G.; Kim, S.; Hwang, I.; Im, S.-O.; Park, H.-M.; Kim, N.-Y.; Kim, M.-J.; Lee, D.; Kwak, S.-N.; et al. The First Population Simulation for the Zalophus japonicus (Otariidae: Sea Lions) on Dokdo, Korea. J. Mar. Sci. Eng. 2022, 10, 271. https://doi.org/10.3390/ jmse10020271

Academic Editor: Roberto Carlucci

Received: 10 January 2022

Accepted: 11 February 2022

Published: 15 February 2022

Publisher's Note: MDPI stays neutral with regard to jurisdictional claims in published maps and institutional affiliations.

Copyright: (C) 2022 by the authors. Licensee MDPI, Basel, Switzerland. This article is an open access article distributed under the terms and conditions of the Creative Commons Attribution (CC BY) license (https:// creativecommons.org/licenses/by/ $4.0 /)$.
1 Department of Oceanography, Pusan National University, Geumjeong-gu, Busan 46241, Korea; yoonji051@pusan.ac.kr (Y.-J.L.); knayo@pusan.ac.kr (N.-Y.K.); mjune@pusan.ac.kr (M.-J.K.); ldasom91@naver.com (D.L.)

2 Finance-Fishery·Manufacture Industrial Mathematics Center on Big Data, Pusan National University, Geumjeong-gu, Busan 46241, Korea; giphil@pusan.ac.kr

3 Department of Mathematics, Pusan National University, Geumjeong-gu, Busan 46241, Korea; sangil.kim@pusan.ac.kr

4 Marine Ecosystem Management Team, Korea Marine Environment Management Corporation, Yeongdo-gu, Busan 49111, Korea; ishwang@koem.or.kr (I.H.); san94@koem.or.kr (S.-O.I.); shrimppark@koem.or.kr (H.-M.P.)

5 Environ-Ecological Engineering Institute Company Limited, Haeundae-gu, Busan 48058, Korea; seoknam@eeei.kr

* Correspondence: sanglee@pusan.ac.kr; Tel.: +82-51-510-2256

\begin{abstract}
The Japanese sea lion (Z. japonicus) has been regarded as an extinct species since the last report on Dokdo in 1951. Not much ecological information on the Z. japonicus on Dokdo (hereafter Dokdo sea lion) is currently available. Using a discrete time stage-structured population model, we reconstructed the Dokdo sea lion population to explore the effect of human hunting pressure on them. This study provides the first estimate for the Dokdo sea lion population from 1900 to 1951 . The reconstructed capture numbers of the Dokdo sea lion and the parameters estimated in this study were well matched with the recorded numbers and ecological parameters reported previously for the Californian sea lion. Based on the reconstructed population, their number rapidly declined after hunting started and it took less than 10 years for a $70 \%$ decline of the initial population, which would be considered to be an extinction risk. Since some caveats exist in this study, some caution about our results is necessary. However, this study demonstrates how rapidly human over-hunting can cause the extermination of a large local population. This study will be helpful to raise people's awareness about endangered marine animals such as local finless porpoises in Korea.
\end{abstract}

Keywords: sea lions; Dokdo; marine mammals; pinnipeds

\section{Introduction}

The genus Zalophus consists of the Japanese (Z.japonicus), California (Z. californianus), and Galapagos (Z. wollebaeki) sea lions which are closely related species $[1,2]$. The three species were typically considered to be isolated geographically since their geographic distributions are widely separated from the temperate western (Z. japonicus) and eastern (Z. californianus) North Pacific to the tropical Galapagos Archipelago (Z. wollebaeki) [2]. Based on the results from ancient DNA analysis extracted from skeletal remains of Japanese sea lions, Sakahira and Niimi [3] reported that Z. japonicus diverged from Z. californianus approximately 2.2 million years ago in the late Pliocene epoch. Recently, Kim et al. [4] found that Z. japonicus was closely related to Z californianus with $98.61 \%$ sequence identity based on the first completed mitochondrial genome sequence of $Z$. japonicus recently excavated from an archaeological site on Ulleungdo, Korea (Figure 1). 


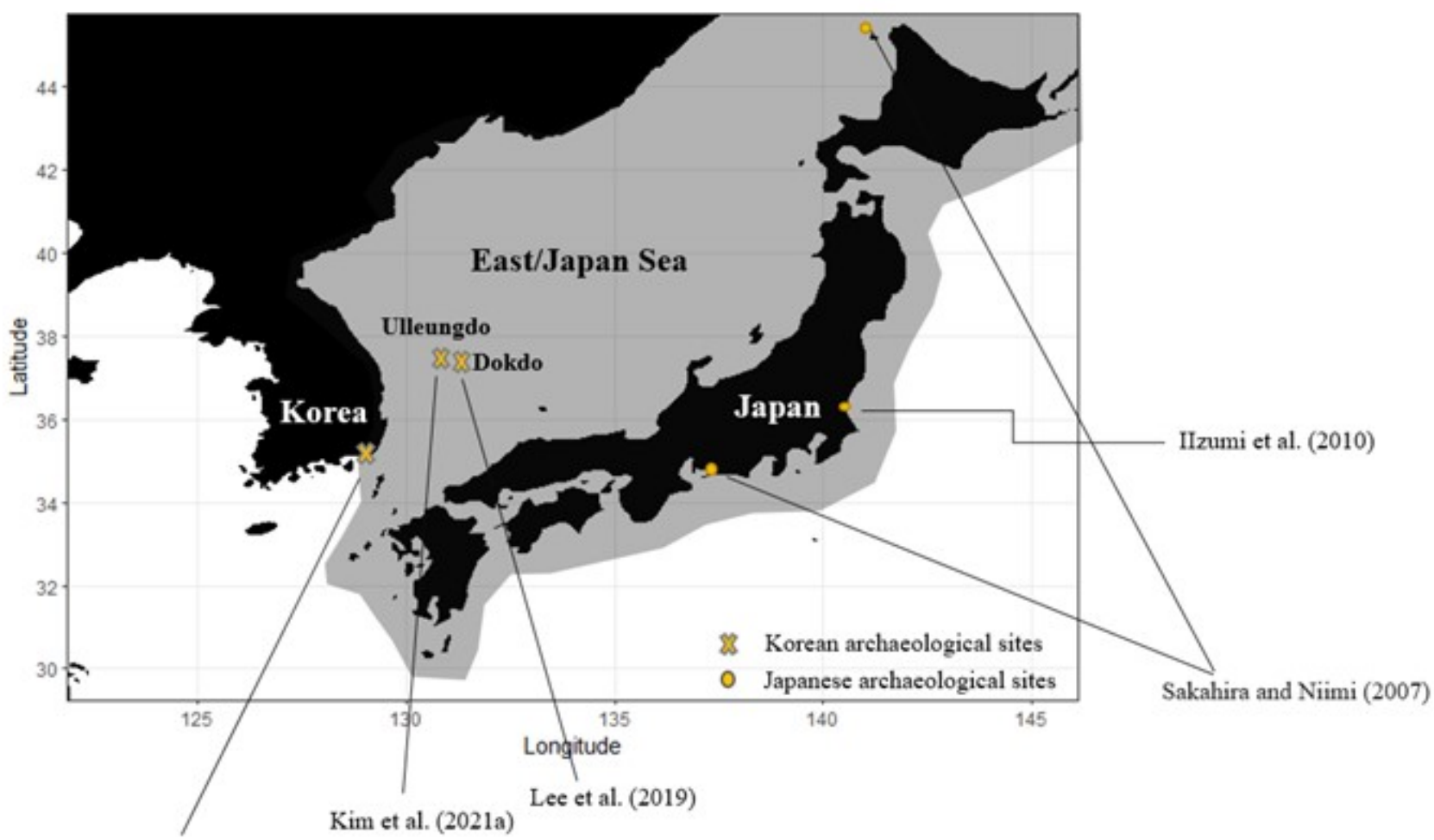

Choy and Richards (2010)

Figure 1. The possible historical distribution range from Melin et al. [5] (grey color) and archaeological sites of the Zalophus japonicus in the East/Japan Sea from [3,4,6-8].

Among the three genera of Zalophus, Japanese sea lions have been regarded as an extinct species since the last report of 50 to 60 sea lions on Dokdo in 1951 [1]. Only one last Z. japonicus was reported in the northern coastal area in Hokkaido in 1974, but specific identification was not conducted so that misidentification could have occurred [9]. Reynolds et al. [10] and Kovacs et al. [11] reported that the Japanese sea lion has been extinct for the past 60 years. However, several international research collaborations have been conducted to detect whether this species are still alive along the northwest Pacific region including Ulleungdo and Dokdo in Korea [12-14]. Although some unofficial reports of observations for the species were reported, it is considered that there may have been confusion with Steller's sea lion or the Northern fur seal [2] which have been occasionally observed along the eastern coast in Korea [15]. Recently, the International Union for Conservation of Nature (IUCN) listed Z. japonicus as an extinct species [16].

Previously, Z. japonicus had been distributed along the northwest Pacific coastline ranging from Russia (Kamchatka and Sakhalin) to coastal waters of Japan and Korea and especially Ulleungdo and Dokdo, which had been regarded as one of the main Korean habitats in the 1900s [1]. Based on numerous historical local Japanese names based on the sea lion, a large number of sea lions have observed in the Japanese coastal regions since prehistoric times ([17]; Figure 1). In Korea, several historical caves named after sea lion have been continuously used by local people on Ulleungdo and Dokdo [15,18]. Subsistence sea lion hunting by native coastal communities since prehistoric times was conducted in Korea [7] and Japan [3] as evidenced by various archaeological evidence. Choy and Richards [7] found that main food sources for the prehistoric coastal communities in the southeastern coast of the Korean Peninsula were marine animals and large marine mammals including sea lions, based on isotopic compositions of bone collagen excavated from an archaeological site in Yeongdo-gu, Busan city, South Korea. This prehistoric subsistence hunting probably did not have a large effect on the population but relatively modern commercial harvesting hunting with modern sophisticated techniques caused a 
substantial decline in the population of sea lions in southern California and Mexico [2]. The population of the Japanese sea lion had nearly disappeared in the coastal waters of Japan by the early 1900s mainly due to over-catching by Japanese fishermen for their meat and oil [17]. This commercial hunting pressure appears to have reduced the geographical ranges of Z. japonicus to remote islands in the East/Japan Sea, namely Ulleungdo and Dokdo which were previously pristine and unpopulated $[6,18]$. The population of Z.japonicus on Dokdo drastically declined during the early decades of the 1900s since the Japanese commercial harvesting started in 1904 and only 50 to 60 animals were reported by the 1950s (Figure 2; $[2,6,18])$. However, the major potential reasons for the drastic decline in their population have not confirmed whether there were some environmental changes in their major habitats during El Niño events or human over-catching [18]. The environmental changes could cause a reduction in major prey and a change in their behavioral responses (e.g., migration, breeding, etc.) during El Niño events [2].

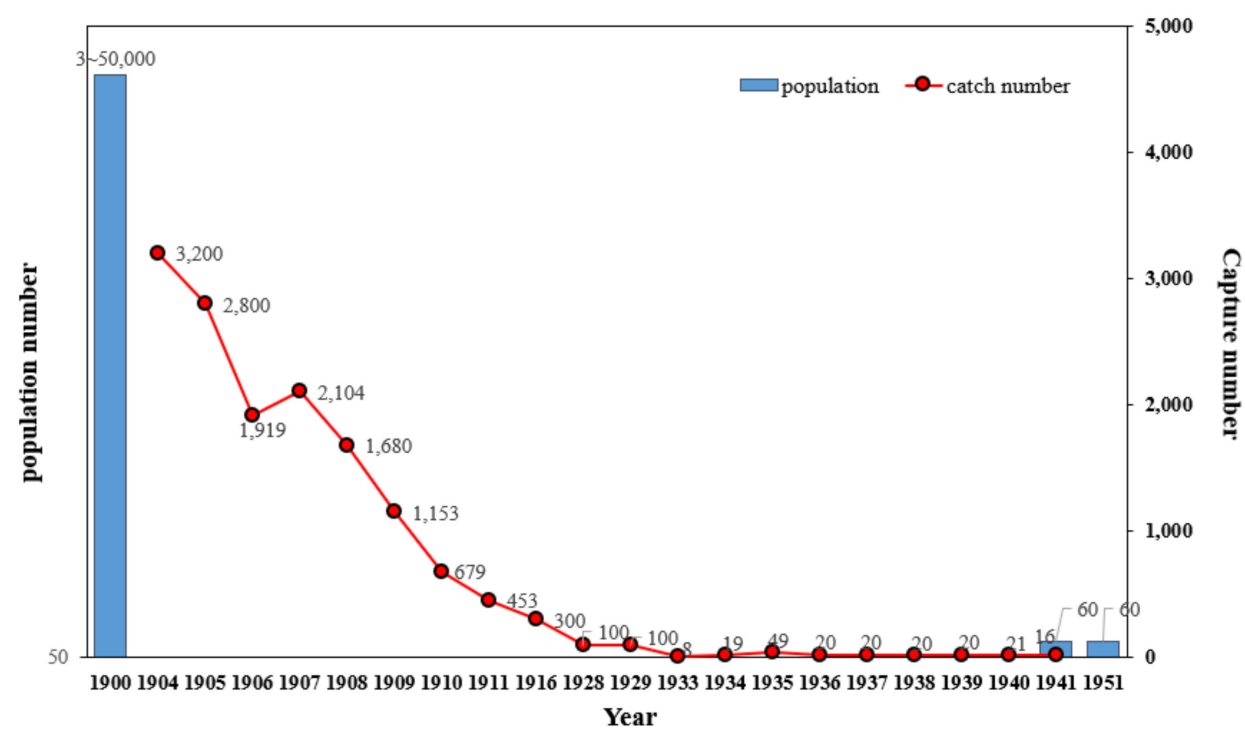

Figure 2. The recorded populations and annual capture numbers of the Dokdo sea lion from 1900 to 1951. The population numbers were from $[1,2,6,18]$ and the annual capture numbers from 1904 to 1941 were based on $[13,19]$.

Not much information on the ecology and specific population of Z. japonicus is currently available, since they had been extinct before various scientific research works were conducted. Based on the fragmented historical and official records from Korea and Japan, we reconstructed the population of $Z$. japonicus on Dokdo (hereafter the Dokdo sea lion) using population models with ecological parameters of the California sea lion (Z. californianus) which is genetically closely related to the Dokdo sea lion [3,4]. The main objectives of this study was to reconstruct the population size of the Dokdo sea lion from a simple fitting curve with the existing historical records and to explore the effect of human hunting pressure on the population. This study will be helpful to raise people's awareness for critically endangered marine mammals.

\section{Materials and Methods}

\subsection{Historical Hunting Records}

At the current stage, limited quantitative data on the Dokdo sea lion and their capture numbers by Japanese fisherman are available. The reported populations of the Dokdo sea lion in 1900, 1941, and 1951 and the annual capture numbers from 1904 to 1941 were obtained from the historical records and unpublished documents from Korea and Japan $([2,13,14,18]$; Figure 1). 


\subsection{Stage-Structured Model}

A discrete time stage-structured population model was applied for the Dokdo sea lion in this study. The discrete time stage-structured population model has been described in various articles and textbooks of fishery mathematical modelling [20-22]. The model is divided into two groups of sea lion compartments, immature $(x)$ and mature $(y)$ groups, and the difference equations for the two groups are as follows:

$$
\begin{gathered}
x_{t+1}=b e^{-\left(M_{y}+F_{y}\right)} y_{t}-(1-a) e^{-\left(M_{x}+F_{x}\right)} x_{t} \\
y_{t+1}=a e^{-\left(M_{x}+F_{x}\right)} x_{t}-e^{-\left(M_{y}+F_{y}\right)} y_{t}
\end{gathered}
$$

In model (1), $\mathrm{b}$ is the birth rate of the immature at time $\mathrm{t}, M_{x}$ and $M_{y}$ represent the natural mortality rates of immature and mature groups, respectively. $F_{x}$ and $F_{y}$ represent the catch mortality rates of the two groups, respectively.

Specifically, $e^{-\left(M_{x}+F_{x}\right)}$ and $e^{-\left(M_{y}+F_{y}\right)}$ describe the survival probabilities for immature and mature individuals, respectively. $b e^{-\left(M_{y}+F_{y}\right)} y_{t}$ represents the birth population into the immature by surviving mature individuals. $a e^{-\left(M_{x}+F_{x}\right)} x_{t}$ is the number of individuals which become mature from the surviving immature population where $a$ is the proportion of immature individuals becoming mature individuals. In our model, no large immigration and emigration were considered since the Ulleungdo and Dokdo as major habitats for the Dokdo sea lion are remote islands in the East/Japan Sea.

\subsection{Parameter Estimation}

We estimated five parameters, the birth rate $(b)$, natural mortalities of immature and mature $M_{x}, M_{y}$ and natural mortalities of immature and mature $F_{x}, F_{y}$, by fitting the actual catch data for the Dokdo sea lion by using a MATLAB-embedded function, lsqcurvefit. This is a least square estimation method for the five parameters that minimizes the gap of catch data between the actual data and the simulated results from Equation (1). The simulated results of the catch at time $t$, denoted by $F_{t}$ for year were calculated as:

$$
F_{t}=\frac{F_{x}}{F_{x}+M_{x}}\left(1-e^{-\left(M_{x}+F_{x}\right)}\right) x_{t}+\frac{F_{y}}{F_{y}+M_{y}}\left(1-e^{-\left(M_{y}+F_{y}\right)}\right) y_{t}
$$

The Dokdo sea lions were distinguished between immature and mature based on an age of five years of old when reproduction becomes possible, and the value of a is expressed as $1 / 5$ [2].

\section{Results and Discussion}

The historical geographical distribution of Z. japonicus were the eastern coasts of Korea, coastal waters of Japan, and the Russian territories such as southwestern Sakhalin, Kuril's islands, and Kamchatka ([1]; Figure 1). In the mid-1800s, the population of Z. japonicus was estimated in a range of 30,000-50,000 around Korea and Japan [2]. They hunted for prey sometimes a long distance away but did not seasonally migrate [16]. Although prehistoric subsistence hunting by native coastal communities had been conducted in Korea and Japan [3,17], a substantial decline of the Dokdo sea lion population in the early 1900s could have been caused by the over-catching by Japanese fishermen for their meat and oil [17], which had happened in southern California and Mexico [2,5]. Based on the historical and official bibliographic records $[2,6,7,19]$, the populations and annual capture numbers of the Dokdo sea lion were plotted from 1900 to 1951 (Figure 2). Japanese fisherman commercially started to hunt a large number of Dokdo sea lions (3200 individuals) in 1904 and their hunting number declined to a couple of hundred by the early 1910s after 10 years of hunting (Figure 2). A major hunting of sea lions was conducted by the Japanese Jukdo Fishing Joint Stock Company during the 1904-1925 period and then the hunting was irregularly done by the Okido people [19]. They hunted mostly females and sub-adults which annually increased up to $86 \%$ in 1908 since the large male sea lions were hard to catch [19]. Even after 
the large decline in the population (based on their capture number), they still caught a small number live for circus performances until 1941 rather than hunting for their products [18]. A total of approximately 15,000 Dokdo sea lions were hunted for the 40-year Japanese fishing period from 1904 to 1941. After hunting stopped, 50-60 individuals, which was approximately $0.2 \%$ of the total population at the beginning of the commercial hunting in 1904, were reported in 1951 [1].

The reconstructed capture numbers of the Dokdo sea lion are matched well with the recorded numbers (Figure 3). The parameters estimated in this study (Table 1) were within the ranges reported previously for the California sea lion [23-25]. For example, the birth rate for the female California sea lion ranged from 38\% to 54\% at Los Islotes, Baja California Sur, Mexico, from the 1978 to 1982 study period [24]. Actually, the birth rate can vary with age, being significantly higher rates in young and middle-age groups (0.52-0.80) than the older age-groups (0.06) [25]. For the natural mortality, 50\% and 10\% of immature and mature sea lions, respectively, were estimated in this study. Normally, the natural mortality of the California sea lion is substantially higher in immature pup group during their pupping season [23]. The annual pup mortality of the California sea lion averaged from 3 years observation is approximately 50\% at Los Islotes, Baja California Sur, Mexico [24]. The fishing mortality was estimated substantially higher in mature groups than immature groups. Given these parameters, the reconstructed population estimates matched well with several data points for the numbers of the Dokdo sea lion (Figure 4). Based on the reconstructed population of the Dokdo sea lion, their number rapidly declined to approximately $50 \%$ of the initial population in 1908 after 5 years' fishing activity and to approximately $6 \%$ of the initial population by the end of 20 years fishing in 1923 . Since there is no quantitative time-series data on the actual population size of the Dokdo sea lion, the precision of the results for their historical population reconstruction might be low. Several caveats are associated with the results in this study. Firstly, the records on the historical population estimates of the Dokdo sea lion are not quantitative. Secondly, our simple fitting curve population models have several assumptions for ecological parameters estimated for the Dokdo sea lion since not much information is currently available for a robust model. Moreover, no other environmental conditions were considered in this study for their population dynamics. Therefore, our results in this study should be considered with caution since our approach to reconstructing the historical population estimates of the Dokdo sea lion is a simple mathematical technique.

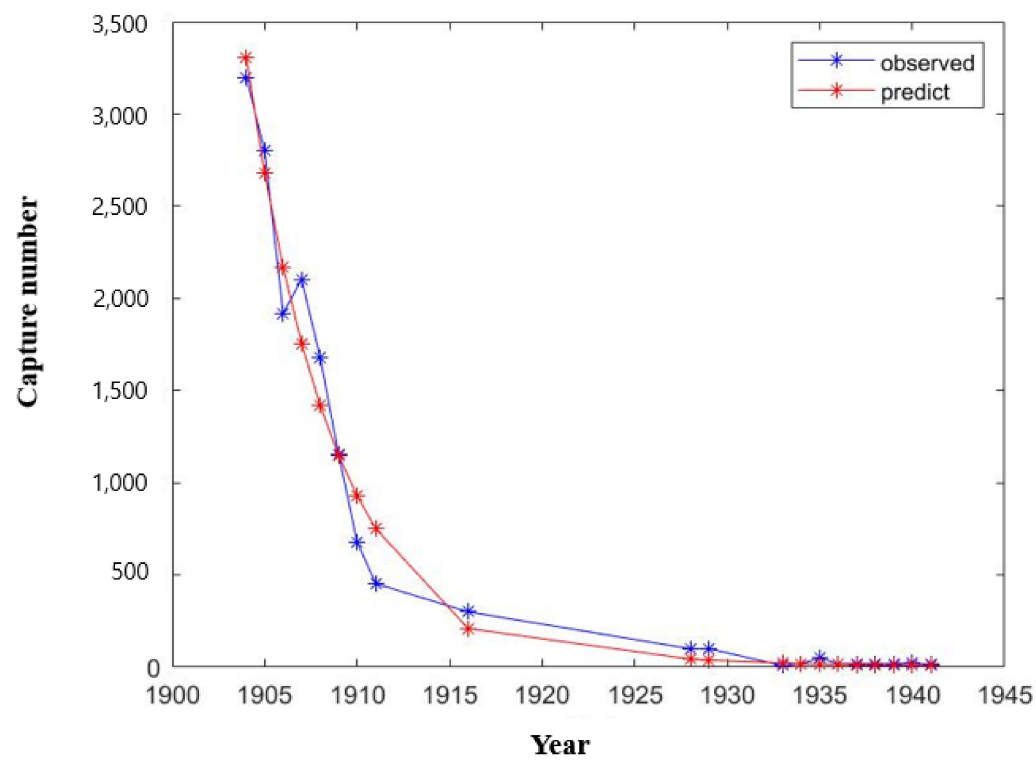

Figure 3. The comparison between observed and estimated annual capture numbers of the Dokdo sea lion. 
Table 1. Description of discrete time stage-structured model parameters.

\begin{tabular}{cccc}
\hline Parameter & Description & Value & Reference \\
\hline$b$ & Birth rate & 0.5 & estimated \\
$a$ & The proportion of immature to mature & $1 / 5$ & Heath and Perrin (2009) \\
$M_{x}$ & The natural mortality of the immature individuals (year ${ }^{-1}$ ) & 0.5 & estimated \\
$M_{y}$ & The natural mortality of the mature individuals (year ${ }^{-1}$ ) & 0.1 & estimated \\
$F_{x}$ & The fishing mortality of the immature individuals (year ${ }^{-1}$ ) & 0.0138 & estimated \\
$F_{y}$ & The fishing mortality of the mature individuals (year ${ }^{-1}$ ) & 0.2428 & estimated \\
\hline
\end{tabular}

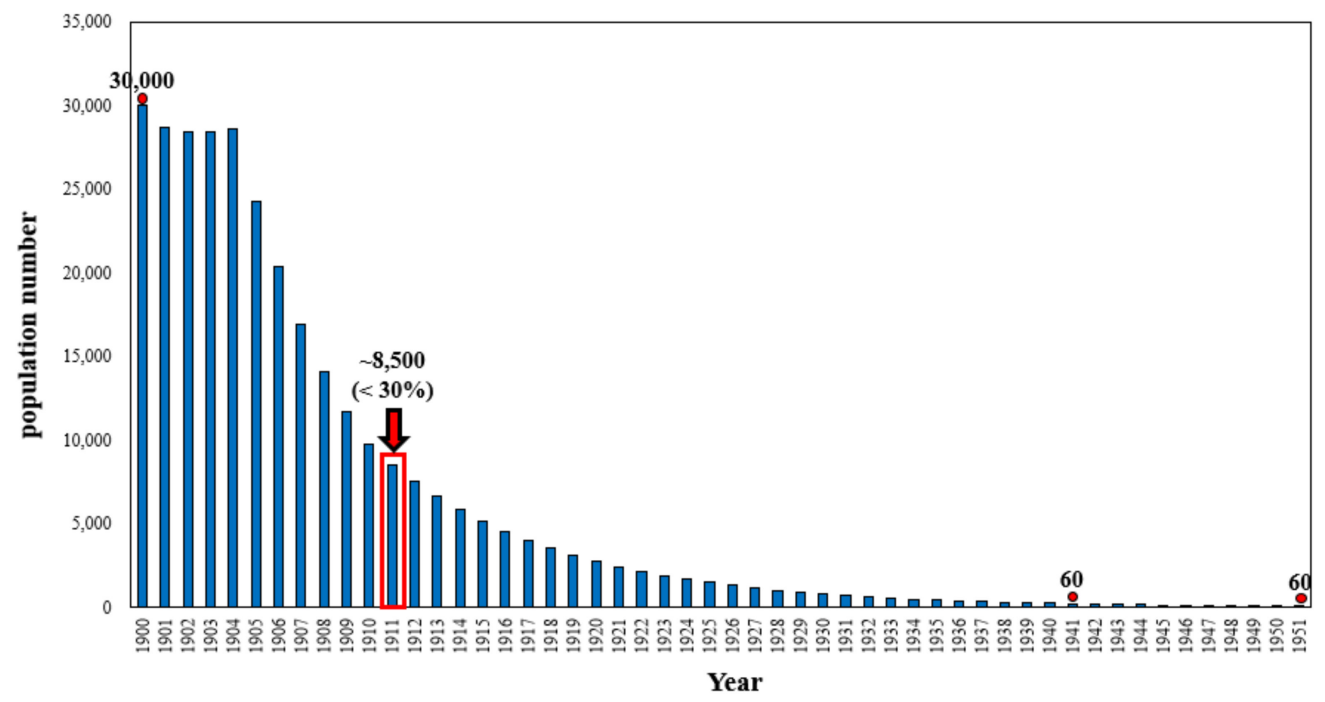

Figure 4. The reconstructed population numbers of the Dokdo sea lion from 1900 to 1951. The red circles are population numbers reported previously.

A sudden major decline in a population to extinction generally results from short-term natural catastrophic or anthropogenic events or chronic, gradual decline of a population [26]. Mangel and Tier [27] concluded that catastrophic events could cause a sudden major decline in population for a relatively short time period and thus be a more important factor for determining their persistence over time than any other factor. Catastrophic events usually control the birth and death processes which affects the dynamics and extinction of a population [26]. A population with a $70 \%$ decline for years would be considered to be an extinction risk [26]. Based on our simulation result, the population of the Dokdo sea lion was less than $30 \%$ in 1911 within the 10-year fishing period (Figure 4). It took only less than 10 years for the $70 \%$ decline of the Dokdo population by Japanese commercial hunting. Four possible mechanisms for human-caused extinction are over-hunting, which is the most obvious extinction mechanism, introduction of new species, habitat destruction which is currently a major human-caused extinction risk, and secondary cascade extinction [28]. The result in this study obviously showed that the extinction of a large local population of the Dokdo sea lion could have been caused by primary human-caused extermination, over-hunting. However, any environmental change was not considered for our discrete time stage-structured population model. The dramatic decline of the Dokdo sea lion population could have been caused by the increase in sea surface temperature. For the California sea lion, the annual population growth rate can be largely influenced by the increasing sea surface temperature which is strongly associated with major prey for the sea lions in the highly productive California coastal waters [29,30]. The latitudinal difference in resource availability can influence foraging behavior and thus survival rate of local resident sea lion species associated with a changing environment [29]. Indeed, the local productivity in Ulleungdo and Dokdo are lower than what is observed in California or Baja California [31,32]. Moreover, the Galapagos sea lion had a smaller population than the California sea lion [5] and one that was probably more vulnerable to extinction than the 
California sea lion. The Dokdo sea lion in the mid-1800s once had a similar population size $(30,000-50,000)$ [2] as the Galapagos sea lion (approximately 40,000) in 1978. Therefore, the Dokdo sea lion would be even more vulnerable to extinction with a changing environment.

We examined the population dynamics of the Dokdo sea lion to determine the major population decline and the recovery population simulations with several fishing ban scenarios during the Japanese fishing period for 40 years (Figure 5). If we assumed that they stopped their hunting in 1910 after 6 years of hunting, then it would take approximately 120 years to fully recover the initial population in 1900 (Figure 5). If they stopped after 14 years hunting in 1920, it would take approximately 220 years for the population recovery (Figure 5). Based on the results from the simple simulations, it is very surprising to realize how much heavy commercial fishing impacts the natural population recovery of the specific target species. Recently, critically important ecological roles of marine mammals were reported in various marine ecosystems [33-35]. Their ecological roles could vary from bottom-up stimulation of phytoplankton production and further climate regulation through a whale pumping mechanism to top-down predators affecting the abundance and spatial distribution of their prey and, consequently, hierarchical ecosystem structure [34,35]. Unfortunately, we cannot know the ecological roles of the Dokdo sea lion on the East/Japan Sea ecosystem since they were extinct before scientific research on them was undertaken.
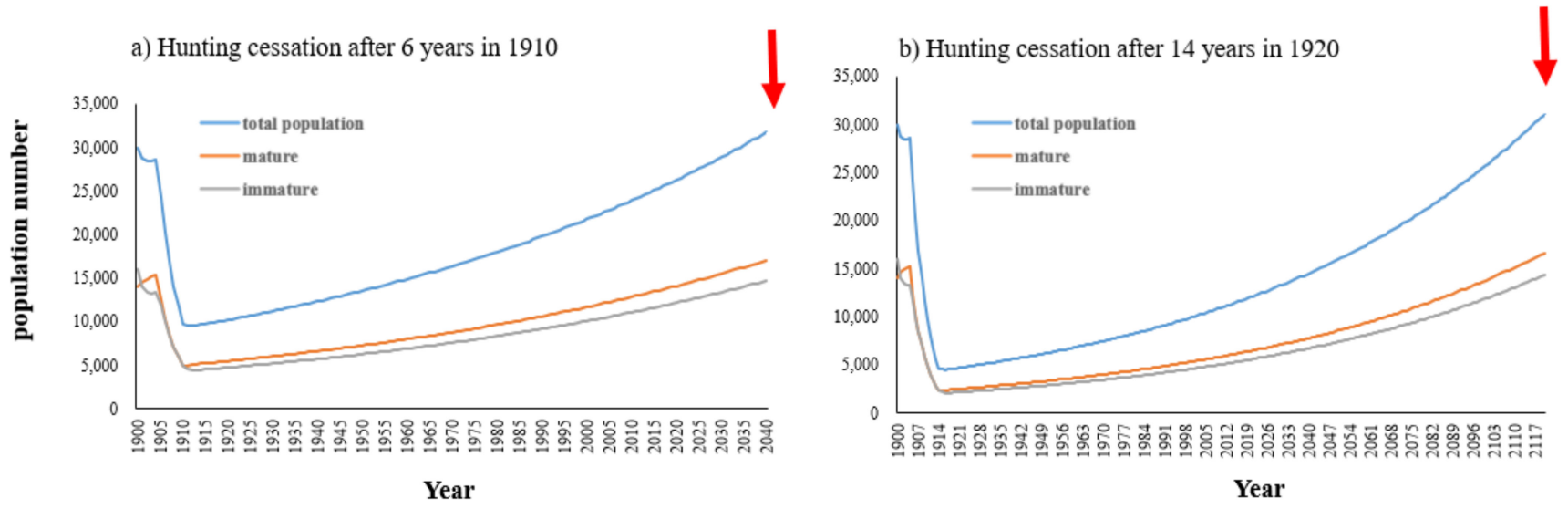

Figure 5. The population recovery scenarios for the Dokdo sea lion. (a) hunting cessation after 6 years in 1910, (b) hunting cessation after 14 years in 1920.

In this study, we demonstrated the huge impact of human hunting on the local population of the Dokdo sea lion which is consequently extinct, using a simple fitting curve method based on the fragmented historical and official records on the Dokdo sea lion population. This study provides the first estimate for the annual population size of the Dokdo sea lion from 1900 to 1951. This simple approach in this study could be extended to other pinnipeds and marine mammals. The risk of extinction is a globally important concern for various marine mammals, in particular otariids [26]. It is essential to understand major extinct causes and potential subsequent consequences of the extinct species for conservation biology [36]. Given the importance of over-catching for the extinction of the Dokdo sea lion, the analysis conducted in this study should be considered for other local marine mammals including pinnipeds. For example, a large number of local finless porpoises (Neophocaena asiaeorientalis) are distributed along coastal areas in Korea. Approximately 36,000 finless porpoises were estimated in the west coast of Korea in 2004 based on models of the detection function in a line transect [37]. However, the population density of the species rapidly declined by approximately $70 \%$ in less than one decade from 2004 to 2011 mainly due to bycatching related to stranding and fishing gear [38]. In the Bohai Sea, China, approximately 8000 spotted seals in the 1940s declined to 2000 in the 1980s due to human hunting and then less than 1500 were estimated to remain in recent years [39,40]. Because of their habitat loss and human impacts, the spotted seal is categorized as a critically endangered species in China and Korea [41]. Approximately 
400 spotted seals are annually observed along the coast of Baengnyeong islands and some small population group (around 10) of the seals are found in Galolim Bay, South Korea [15]. Therefore, it is important to protect marine mammals such as finless porpoises and spotted seals which has been declining in numbers in coastal areas in Korea and China. In the case of marine mammals, the increase in the population does not appear in a short period of time due to the characteristics of their life history by which one female gives birth to one pup and it takes a long time to nurse the young pup. Indeed, it is quite surprising to realize how long it would take for their population recovery based on the simple simulations in this study (Figure 5). Moreover, a decline in the population could be predicted to be apparent if human threats are added [2,5]. Currently, marine mammals are designated and protected as marine protection organisms in Korea but research on marine mammals are insufficient, so information on the biological characteristics or distribution status of most species is not well understood [42]. Therefore, in order to effectively conserve marine mammals in Korea, it is necessary to seek realistic management methods and to conduct various research approaches more actively [15]. A failure to do so may result in the local extinction of marine mammal species in Korea, as with the Dokdo sea lion. We should learn an invaluable lesson from the historical human-caused extinction of the Dokdo sea lion.

Author Contributions: Conceptualization, Y.-J.L. and S.-H.L.; methodology, G.C., S.K. and S.-H.L.; validation, Y.-J.L. and S.-H.L.; formal analysis, G.C. and S.K.; investigation, Y.-J.L., N.-Y.K., M.-J.K., G.C., I.H., S.-O.I., H.-M.P., S.-N.K. and D.L.; data curation, Y.-J.L. and S.-H.L.; writing-original draft preparation Y.-J.L. and S.-H.L.; writing-review and editing, S.-H.L.; visualization, Y.-J.L. and S.-H.L.; supervision, S.-H.L.; project administration, I.H., S.-O.I., H.-M.P. and S.-H.L.; funding acquisition, I.H., S.-O.I., H.-M.P., S.-N.K. and S.-H.L. All authors have read and agreed to the published version of the manuscript.

Funding: This research was supported by the "Investigation on the habitat of pinnipeds in the Korean East Sea, 2021" funded by the Ministry of Oceans and Fisheries, Korea.

Institutional Review Board Statement: Not applicable.

Informed Consent Statement: Not applicable.

Data Availability Statement: Not applicable.

Acknowledgments: The authors would like to thank the anonymous reviewers and the handling editors who dedicated their time to providing the authors with constructive and valuable recommendations.

Conflicts of Interest: The authors declare no conflict of interest.

\section{References}

1. Rice, D.W. Marine Mammals of the World: Systematics and Distribution; Special Publication Number 4, The Society for Marine Mammalogy; Allen Press: Lawrence, KS, USA, 1998; pp. $29-42$.

2. Heath, C.B.; Perrin, W.F. California, Galapagos, and Japanese sea lions: Zalophus californianus, Z. wollebaeki, and Z. japonicus. In Encyclopedia of Marine Mammals; Elsevier: Amsterdam, The Netherlands, 2009; pp. 170-176.

3. Sakahira, F.; Niimi, M. Ancient DNA analysis of the Japanese sea lion (Zalophus californianus japonicus Peters, 1866): Preliminary results using mitochondrial control-region sequences. Zoolog. Sci. 2007, 24, 81-85. [CrossRef] [PubMed]

4. Kim, E.-B.; Kim, M.J.; Hwang, I.; Park, H.-M.; Lee, S.H.; Kim, H.-W. The complete mitochondrial genome of Japanese sea lion, Zalophus japonicus (Carnivora: Otariidae) analyzed using the excavated skeletal remains from Ulleungdo, South Korea. Mitochondrial DNA Part B 2021, 6, 3184-3185. [CrossRef] [PubMed]

5. Melin, S.R.; Trillmich, F.; Aurioles-Gamboa, D. California, Galapagos, and Japanese Sea Lions: Zalophus californianus, Z. wollebaeki, and Z. japonicus. In Encyclopedia of Marine Mammals; Elsevier: Amsterdam, The Netherlands, 2018; pp. $153-157$.

6. Lee, S.-R.; Kim, Y.-B.; Lee, T. The first molecular evidence of Korean Zalophus japonicus (Otariidae: Sea lions) from the archaeological site of Dokdo island, Korea. Ocean Sci. J. 2019, 54, 497-501. [CrossRef]

7. Choy, K.; Richards, M.P. Isotopic evidence for diet in the Middle Chulmun period: A case study from the Tongsamdong shell midden, Korea. Archaeol. Anthropol. Sci. 2010, 2, 1-10. [CrossRef]

8. IIzumi, K.; IIzumi, K.; Koda, Y.; Koike, W.; Nishimoto, T.; Ando, H.; Date, M. Latest Pleistocene Japanese Sea lion(Otariidae) fossil from the riverbed of the Hanamurogawa River west of Kasumigaura Lake, Ibaraki Prefecture. J. Geol. Soc. Japan. Tokyo 2010, 116, 243-251. [CrossRef]

9. Itoo, T. Miscellaneous on the Japanese sea lion Zalophus californianusc japonicus. Mammal Sci. 1979, 19, 27-39. [CrossRef] 
10. Reynolds, J.E., III.; Marsh, H.; Ragen, T.J. Marine mammal conservation. Endanger. Species Res. 2009, 7, 23-28. [CrossRef]

11. Kovacs, K.M.; Aguilar, A.; Aurioles, D.; Burkanov, V.; Campagna, C.; Gales, N.; Gelatt, T.; Goldsworthy, S.D.; Goodman, S.J.; Hofmeyr, G.J.G. Global threats to pinnipeds. Mar. Mammal Sci. 2012, 28, 414-436. [CrossRef]

12. Jackson, P.F.R. Hunt for the Japanese Sea-lion. Environ. Conserv. 1977, 4, 290. [CrossRef]

13. ME (Ministry of Environment). Study on the Monitoring of Marine Mammals (Pinniped) in the East Sea and Management Plans; NIER (National Institute of Environmental Research): Incheon, Korea, 2007.

14. NIBR (National Institute of Biological Resources). Investigation and Network Construction for the Restoration of Endangered Marine Mammals (Pinniped); NIBR: Incheon, Korea, 2010.

15. Kim, H.W.; Lee, S.; Sohn, H. A Review on the Status of Pinnipeds in Korea. Korean J. Fish. Aquat. Sci. 2021, 54, $231-239$.

16. Lowry, L. Zalophus japonicus. The IUCN Red List of Threatened Species. 2017. Available online: https://www.iucnredlist.org/ species/41667/113089431; (accessed on 5 January 2022).

17. Nakamura, K. An essay on the Japanese Sea Lion, Zalophus californianus japonicus, living on the seven islands of Izu. Bull. Kanagawa Prefect. Museum (Nat. Sci.) 1991, 20, 59-66.

18. Joo, K.H. The History of Extinction of Dokdo Sea Lions; Seohaemunjip: Seoul, Korea, 2016.

19. Kim, S. Japan [Sea Otter and Fur Seal Fishing Law (臘虎肭獸獵法)] and Dokdo Sea Lion Fishing. J. Jpn. Cult. 2016, 70, 25-40.

20. Liu, S.; Chen, L.; Agarwal, R. Recent progress on stage-structured population dynamics. Math. Comput. Model. 2002, 36, 1319-1360. [CrossRef]

21. Jung, S.; Choi, I.; Jin, H.; Lee, D.; Cha, H.; Kim, Y.; Lee, J. Size-dependent mortality formulation for isochronal fish species based on their fecundity: An example of Pacific cod (Gadus macrocephalus) in the eastern coastal areas of Korea. Fish. Res. 2009, 97, 77-85. [CrossRef]

22. Hilborn, R.; Walters, C.J. Quantitative Fisheries Stock Assessment: Choice, Dynamics and Uncertainty; Springer Science Business Media: Berlin/Heidelberg, Germany, 2013; ISBN 1461535980.

23. Brownell, R.L., Jr.; LeBoeuf, B.J. California sea lion mortality: Natural or artifact. In Biological and Oceanographical Survey of the Santa Barbara Channel Oil spill 1969-1970; Allan Hancock Foundation: Los Angeles, CA, USA, 1971; pp. 287-305.

24. Aurioles, D.; Sinsel, F. Mortality of California Sea Lion Pups at Los Islotes, Baja California Sur, Mexico. J. Mammal. 1988, 69, 180-183. [CrossRef]

25. Hernández-Camacho, C.J.; Aurioles-Gamboa, D.; Gerber, L.R. Age-specific birth rates of California sea lions (Zalophus californianus) in the Gulf of California, Mexico. Mar. Mamm. Sci. 2008, 24, 664-676. [CrossRef]

26. Gerber, L.R.; Hilborn, R. Catastrophic events and recovery from low densities in populations of otariids: Implications for risk of extinction. Mamm. Rev. 2001, 31, 131-150. [CrossRef]

27. Mangel, M.; Tier, C. Four facts every conservation biologists should know about persistence. Ecology 1994, 75, 607-614. [CrossRef]

28. Diamond, J.M. The present, past and future of human-caused extinctions. Philos. Trans. R. Soc. London B Biol. Sci. 1989, 325, 469-477.

29. Villegas-Amtmann, S.; Simmons, S.E.; Kuhn, C.E.; Huckstadt, L.A.; Costa, D.P. Latitudinal range influences the seasonal variation in the foraging behavior of marine top predators. PLoS ONE 2011, 6, e23166. [CrossRef]

30. Laake, J.L.; Lowry, M.S.; DeLong, R.L.; Melin, S.R.; Carretta, J. V Population growth and status of California sea lions. J. Wildl. Manag. 2018, 82, 583-595. [CrossRef]

31. Joo, H.; Park, J.W.; Son, S.; Noh, J.; Jeong, J.; Kwak, J.H.; Saux-Picart, S.; Choi, J.H.; Kang, C.; Lee, S.H. Long-term annual primary production in the Ulleung Basin as a biological hot spot in the East/Japan Sea. J. Geophys. Res. Oceans 2014, 119, 3002-3011. [CrossRef]

32. Kahru, M.; Kudela, R.; Manzano-Sarabia, M.; Mitchell, B.G. Trends in primary production in the California Current detected with satellite data. J. Geophys. Res. Oceans 2009, 114, 1-7. [CrossRef]

33. Roman, J.; McCarthy, J.J. The whale pump: Marine mammals enhance primary productivity in a coastal basin. PLoS ONE 2010, 5, e13255. [CrossRef]

34. Roman, J.; Estes, J.A.; Morissette, L.; Smith, C.; Costa, D.; McCarthy, J.; Nation, J.B.; Nicol, S.; Pershing, A.; Smetacek, V. Whales as marine ecosystem engineers. Front. Ecol. Environ. 2014, 12, 377-385. [CrossRef]

35. Kiszka, J.J.; Heithaus, M.R.; Wirsing, A.J. Behavioural drivers of the ecological roles and importance of marine mammals. Mar. Ecol. Prog. Ser. 2015, 523, 267-281. [CrossRef]

36. Baisre, J.A. Shifting baselines and the extinction of the Caribbean monk seal. Conserv. Biol. 2013, 27, 927-935. [CrossRef]

37. Park, K.J.; Kim, Z.G.; Zhang, C.I. Abundance estimation of the finless porpoise, Neophocaena asiaeorientalis, using models of the detection function in a line transect. Korean J. Fish. Aquat. Sci. 2007, 40, 201-209.

38. Park, K.J.; Sohn, H.; An, Y.R.; Kim, H.W.; An, D.H. A new abundance estimate for the finless porpoise Neophocaena asiaeorientalis on the west coast of Korea: An indication of population decline. Fish. Aquat. Sci. 2015, 18, 411-416. [CrossRef]

39. Jinhai, D.; Feng, S. Estimates of historical population size of harbor seal (Phoca largha) in Liaodong Bay. Mar. Sci. 1991, 3, $26-31$.

40. Yan, H.-K.; Wang, N.; Wu, N.; Lin, W. Abundance, habitat conditions, and conservation of the largha seal (Phoca largha) during the past half century in the Bohai Sea, China. Mammal Study 2018, 43, 1-9. [CrossRef]

41. Won, C.; Yoo, B.-H. Abundance, seasonal haul-out patterns and conservation of spotted seals Phoca largha along the coast of Bak-ryoung Island, South Korea. Oryx 2004, 38, 109-112. [CrossRef]

42. NIBR (National Institute of Biological Resources). Red Data Book of Endangered Mammals in Korea; NIBR: Incheon, Korea, 2012. 